\title{
Letters
}

\section{Voluntary euthanasia in the Netherlands}

\section{SIR}

We broadly welcome Dr van Delden's constructive response ${ }^{1}$ to our paper. ${ }^{2}$ $\mathrm{He}$ nowhere seeks to question our central contention that the guidelines regulating voluntary euthanasia in the Netherlands have been widely breached and have failed to ensure effective control.

He rightly identifies three of our major concerns which support that contention: first, the practice of nonvoluntary euthanasia; secondly, the use of euthanasia when palliative care could have provided an alternative; and, thirdly, the under-reporting of euthanasia by doctors.

He shares our first concern and agrees that non-voluntary euthanasia is "a very serious problem".

As for our second concern, Van Delden does not dispute the frequent performance of euthanasia in cases where palliative care could have alleviated the suffering. His view that this "shift" (his word) is due to an increasing emphasis on patient autonomy is interesting. But whether or not this explanation is accurate, it in no way detracts from the force of our point, which is that, whereas the guidelines require euthanasia to be applied only as a "last resort" in cases of "unbearable suffering", in a considerable number of cases in which palliative care, if made available, could have made the situation bearable, euthanasia was nevertheless performed.

Thirdly, he nowhere seeks to controvert our argument, based on the fact that the majority of cases of euthanasia and assisted suicide are not reported by doctors but are illegally certified by them as deaths by "natural causes", that the reporting procedure has failed to ensure effective control. The useful research by Cuperus-Bosma, ${ }^{3}$ in the paper preceding ours, serves only to confirm our doubts about the efficacy of the Dutch regulatory system. Van Delden notes the introduction of a modified reporting procedure and fairly comments that the effect of this change is not yet clear. There seems little reason to believe, however, that this modification, which renders the procedure even less strict, will ensure any greater control, even if it encourages more reporting,

Van Delden states that "there is no rule that cannot (and will not) be broken" and that this is true of the prohibition on drunk-driving. But it is precisely because of the high value the law has traditionally attached to innocent human life that killing, intentionally or by drunk-driving, is a serious crime. The mere fact that the prohibition will be broken is hardly an argument for relaxing that prohibition. Moreover, decriminalising euthanasia in certain circumstances compounds the difficulties of enforcing the prohibition on killing. It is vain to cite the fact of breach in support of a change which would make breaches not only more likely but also more difficult to detect and prosecute.

Van Delden also poses the question whether the risk of such breaches justifies a prohibition on euthanasia in individual cases. As several distinguished bodies (including the House of Lords Select Committee on Medical Ethics) have concluded, after an exhaustive consideration of the issue, including the evidence from the Netherlands, the answer is "Yes". The further evidence from that country which is the subject of our paper simply confirms the wisdom of that answer. Even if voluntary euthanasia were thought justifiable in hard cases, hard cases, as the Netherlands shows, make bad law.

We would, moreover, take issue with his criticism that our paper is yet another example of comments in which "different types of end-of-life decisions are lumped together". This criticism is entirely without foundation (and gains nothing from his reference to an earlier, unsuccessful attempt to substantiate it. $\left.{ }^{+}\right)$As readers will recall, much of our paper is in fact concerned scrupulously to distinguish between different sorts of end-of-life decisions, not least according to whether they involved an intention to terminate life.

Finally, we would like to comment briefly on the relevance of moral views to the interpretation of empirical data. Van Delden asserts that "the interpretation of these facts remains largely dependent upon our moral views". Moral views (whether for or against) can indeed (though need not) influence not only interpretation of the facts, but also fact-finding. There appears, however, to be a growing acceptance even among those in favour of voluntary euthanasia, reflected in van Delden's response, of the fact that Dutch euthanasia is, as the editorial agrees, "in poor control". That was the central contention of our paper.

Our paper did not in fact seek to explore in depth the separate yet related question whether the Dutch have slid down the "slippery slope" since first permitting voluntary euthanasia in 1984. The editorial points out that, given the absence of statistics before 1984 , there is no way of proving statistically that there is a higher incidence of breach now than then. However, even leaving aside the reasons which would suggest a greater likelihood of breach since 1984 (not least the greater difficulty of enforcing a partial rather than a total ban on doctors killing their patients), the "slippery slope" argument does not depend on statistics. For in its logical form, the argument states that once one accepts voluntary euthanasia, one is, particularly if one brings in the equality principle, logically committed to accepting non-voluntary euthanasia in the same circumstances. Shortly put, if death can be a benefit for a patient with condition $\mathrm{X}$ who can request it, why should it be denied to another patient in precisely the same situation who cannot? ${ }^{6}$ And there is certainly evidence from the Netherlands, independent of statistics, to support this logical slide: evidence indicat- 
ing a growing acceptance of nonvoluntary euthanasia by the Dutch. As Dr Van Delden himself accepted in 1993: "[Is] it not true that once one accepts euthanasia and assisted suicide, the principle of universalizability forces one to accept termination of life without explicit request, at least in some circumstances, as well? In our view the answer to this question must be affirmative".

Finally, we applaud the editorial's emphasis on the need for objectivity in the design, performance and interpretation of studies about euthanasia in the Netherlands. Had this been more widely observed hitherto, the debate would have generated more light than heat. We also welcome Dr van Delden's invited comment and trust that the journal will now lead the way in inviting those critical of the Dutch experience to comment on papers in favour of it. Too many journals have allowed such papers to pass unchallenged.

\section{References}

1 Delden van JM. Slippery slopes in flat countries - a response. Fournal of Medical Ethics 1999;25:22-4.

2 Jochemsen H, Keown J. Voluntary euthanasia under control? Further empirical evidence from the Netherlands. Fournal of Medical Ethics 1999;25:16-21

3 Cuperus-Bosma JM, et al. Assessment of physician-assisted death by members of the public prosecution in the Netherlands. Fournal of Medical Ethic 1999;25:8-15.

4 Keown J. Dances with data: a riposte. Bioethics Research Notes 1994;6:1-2.

5 Gillon R. Euthanasia in the Netherlands - down the slippery slope? fournal of Medical Ethics 1999;25:3-4.

6 Gormally L. Walton, Davies and Boyd and the legalization of euthanasia. In: Keown J, ed. Euthanasia examined. Cambridge: Cambridge University Press, 1995

7 Delden van JM, et al. The Remmelink study: two years later. Hastings Center Report 1993;23,6:24-7.

DR JOHN KEOWN PROFESSOR HENK JOCHEMSEN

Faculty of Lazw, Cambridge University and Lindeboom Institute for Medical Ethics, the Netherlands, respectively.

\section{Medicine, language and ethics}

SIR

A not uncommonly used term in German medical language is the word
"Patientengut", which might be translated as "patient sample" or "case material". The term "Patientengut" is used to describe patients in an institution, patients with a certain diagnosis, or patients with specific clinical similarities shared with all patients of an institution. A search for "Patientengut" in Evaluated Med-Line' over the years 1966-1998 yields 50 results. All these works were published in German, Swiss, or Austrian journals. Respect for our patients should alert us to offending or pejorative ideas, words, and actions. Patients are always human beings, never goods or materials. This is true for a single patient as well as for a group of patients. Hence, I propose banning the term "Patientengut" and substituting for it the words "patientgroups" (Patientenkollektive), “cohort" (Kohorte), or - simply - "patients".

\section{Reference}

1 hhttp:/www.biomednet.com/gateways $\mathrm{db}$ medline

DIETER W ROSSBOTH MD

Carinthian State Hospital, Klagenfurt, A-9026 Klagenfurt, Austria

\section{Life support or molecular maintenance}

SIR

I would like to propose a change of terminology for "life support" in the context of brain dead and permanently vegetative state patients and other severely and irreparably braindamaged patients. It should be designated "molecular maintenance". Removing persons from molecular maintenance would not be as traumatic to physicians, nurses and family members as removing persons from life support. Notwithstanding a more or less lifeless state, health care professionals and relatives are emotionaly charged when confronting "pulling the plug". Large numbers of persons who depend on ventilators and other heroic devices are not, in fact, on life support, but are on these devices merely to sustain cellular integrity. Under the best of circum- stances, regardless of the length time persons are sustained on suct? equipment, they will not be returne to life in any worthwhile sense of thef term.

Virtually every bioethics committe at medical centres throughout the United States confronts the issue of lif support and its termination. To cite $\frac{0}{9}$ specific example: an emergency rook physician was maintaining a $38-y e a \overrightarrow{\vec{b}}$ old woman, brain dead, on a ventilat and other extraordinary measures $\mathrm{f} \overrightarrow{\mathrm{eb}}$ no other reason than waiting for bis for organ harvesting. The physicia was facing an ethical dilemma over the pointlessness of maintaining the peer son for an extended period. Anoth common scenario: a 28-year-old mét with multiple organ failure, maintained on a ventilator and intraveno hydration, comatose with no chance of recovery. Wailing family members wete facing killing a father and husband $\frac{10}{6}$ removing him from "life suppork) rather than withdrawing useless medical intervention so as to provide hiff with a merciful end.

Relatives and friends are made agonise over decisions to remove from so-called "life support" a loved or who has suffered multiple organ fa $\bar{\Phi}$ ure with no chance of return to eva an elemental cognitive state. Tho would have a more relevant reaction they thought of "life support" molecular maintenance; it is huma to the patient and to all parties decision making roles.

The thought of being responsib西 for terminating life is a departure from the human ethos. Endling life violat our ethical and moral righteousness: Thus, to remove someone from "li support" makes people feel inappr priately guilty, which would not be 옥 if the intervention is not life suppos but mere molecular maintenance. $\Phi$ such cases, using the expression "l低 support" should be abandoned favour of a more suitable and correct expression for the sake of both acc racy and compassion for the multitude who will face the wrenching decision to decide the fate of a loved one.

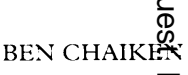

Co-ordinat

Education for Phvsicians on End-of-Life CQ. Phocnix, Arizona, $U \&$ 